\title{
Causal Frequency-Specific Contributions of Frontal Spatiotemporal Patterns Induced by Non-Invasive Neurostimulation to Human Visual Performance
}

\author{
Lorena Chanes, ${ }^{1}$ Romain Quentin, ${ }^{1}$ Catherine Tallon-Baudry, ${ }^{1,2}$ and Antoni Valero-Cabré ${ }^{1,3,4}$ \\ ${ }^{1}$ Université Pierre et Marie Curie, CNRS UMR 7225-INSERM UMRS S975, Groupe Centre de Recherche de l'Institut du Cerveau et la Moelle (ICM), 75013 \\ Paris, France, ${ }^{2}$ Laboratoire de Neurosciences Cognitives, INSERM-ENS UMR960, 75005 Paris, France, ${ }^{3}$ Laboratory for Cerebral Dynamics Plasticity and \\ Rehabilitation, Boston University School of Medicine, Boston, Massachusetts 02118 , and ${ }^{4}$ Cognitive Neuroscience and Information Technology Research \\ Program, Open University of Catalonia (UOC), 08035 Barcelona, Spain
}

Neural oscillatory activity is known to play a crucial role in brain function. In the particular domain of visual perception, specific frequency bands in different brain regions and networks, from sensory areas to large-scale frontoparietal systems, have been associated with distinct aspects of visual behavior. Nonetheless, their contributions to human visual cognition remain to be causally demonstrated. We hereby used non-uniform (and thus non-frequency-specific) and uniform (frequency-specific) high-beta and gamma patterns of noninvasive neurostimulation over the right frontal eye field (FEF) to isolate the behavioral effects of oscillation frequency and provide causal evidence that distinct visual behavioral outcomes could be modulated by frequency-specific activity emerging from a single cortical region. In a visual detection task using near-threshold targets, high-beta frequency enhanced perceptual sensitivity $\left(d^{\prime}\right)$ without changing response criterion (beta), whereas gamma frequency shifted response criterion but showed no effects on perceptual sensitivity. The lack of behavioral modulations by non-frequency-specific patterns demonstrates that these behavioral effects were specifically driven by burst frequency. We hypothesize that such frequency-coded behavioral impact of oscillatory activity may reflect a general brain mechanism to multiplex functions within the same neural substrate. Furthermore, pathological conditions involving impaired cerebral oscillations could potentially benefit in the near future from the use of neurostimulation to restore the characteristic oscillatory patterns of healthy systems.

\section{Introduction}

Evidence in support of the fundamental role played by cerebral oscillations in cognitive processing has strongly emerged in the last decades. In the particular domain of visual perception, prior work has indicated that for different brain regions and systems, from sensory areas to large-scale frontoparietal networks exerting top-down influences on visual processing and behavioral performance, oscillatory activity at specific frequency bands might contribute to distinct aspects of behavior (Donner et al., 2007;

\footnotetext{
Received Sept. 14, 2012; revised Jan. 6, 2013; accepted Jan. 15, 2013.

Author contributions: L.C. and A.V.-C. designed research; L.C., R.Q., and A.V.-C. performed research; L.C. and A.V.-C. analyzed data; L.C., C.T.-B., and A.V.-C. wrote the paper.

This study was funded by FP6 (EU VIth Frame Program) and Agence National de la Recherche Scientifique project eraNET-NEURON BEYONDVIS to A.V.-C. We thank the IFRAD foundation for providing equipment funds. L.C. was supported by a PhD fellowship of the École des Neurosciences de Paris. We are thankful to Dr. B. Dubois for scientific and logistical support in some of the experiments, and to Drs. P. Bartolomeo, S. Meunier, and P. Pradat-Diehl for providing medical supervision during TMS sessions, and Drs. R. Katz and A. Lackmy for technical and logistical support with TMS equipment.

The authors declare no competing financial interests.

Correspondence should be addressed to Dr. Antoni Valero-Cabré, CNRS-INSERM-Université Pierre et Marie Curie, ICM, Equipe Cognition, Neuro-imagerie et maladies du Cerveau; Groupe de Dynamiques Cérébrales, Plasticité et Rééducation, Hôpital de la Salpêtrière, 47-boulevard de I'Hôpital, 75651 Paris Cedex 13, France. E-mail: avalerocabre@gmail.com or avalero@bu.edu.

DOI:10.1523/JNEUROSCI.4401-12.2013

Copyright $\odot 2013$ the authors $\quad 0270-6474 / 13 / 335000-06 \$ 15.00 / 0$
}

Fries, 2009; Siegel et al., 2011). However, the specific role of neural oscillatory frequency remains to be causally isolated.

For nearly two decades, the ability of non-invasive neurostimulation to depolarize local neuronal clusters and interfere with neural processing has been used to establish, in several cognitive domains, causal associations between brain regions and behaviors (Wagner et al., 2007). Recently, by comparing the behavioral modulations obtained at different frequencies, transcranial alternate current stimulation and short-burst and repetitive transcranial magnetic stimulation (TMS) have been used in the investigation of the oscillatory basis of human cognition (Klimesch et al., 2003; Kanai et al., 2008; Romei et al., 2010, 2011; Feurra et al., 2011). More importantly, seminal work performed in this field has demonstrated that uniform TMS bursts can entrain rhythmic brain oscillation patterns tuned to the applied input frequency (Thut et al., 2011).

In the present study, we compared the behavioral impact of frequency-specific (or uniform) and non-frequency-specific (or non-uniform) TMS patterns delivered over a right frontal region to provide causal evidence in humans on the modulatory role of high-beta and gamma activity to distinct aspects of human visual performance. For both frequencies, these two types of TMS patterns had equal duration and number of pulses. Nonetheless, in frequency-specific patterns pulses were uniformly distributed across the duration of the burst, whereas in non-frequency- 
specific patterns, those were delivered at fixed unequal interpulse intervals. This approach warrants the delivery of an identical amount of activity during the same time interval in both types of bursts, isolating the specific impact of stimulation frequency to behavior.

We targeted the right frontal eye field (FEF), a site involved in visuospatial attentional orienting (Corbetta and Shulman, 2002; Corbetta et al., 2008) and conscious perception (Grosbras and Paus, 2003; Moore and Armstrong, 2003; Libedinsky and Livingstone, 2011; Chanes et al., 2012), holding rich interactions with parietal and occipital brain regions, that can engage in high-beta $(30 \mathrm{~Hz})$ and gamma $(50 \mathrm{~Hz})$ oscillatory activity (Fries et al., 2001; Buschman and Miller, 2007; Gregoriou et al., 2009). More specifically, Buschman and Miller (2007) reported a differential involvement of these two oscillation frequencies in a pop-out and a visual search task engaging, respectively, exogenous and endogenous attentional orienting processes, which are known to induce distinct behavioral influences on human visual performance (Chica et al., 2011). We hypothesized that uniform TMS bursts delivered over the right FEF at high-beta versus gamma frequency would yield frequency-specific effects on visual performance, compared with their equivalent non-uniform TMS patterns not tuned to any particular frequency.

\section{Materials and Methods}

Two groups of 14 participants ( 6 women and 8 men and 10 women and 4 men), aged between 19 and 39 years (average of $25 \pm 3$ and $25 \pm 6$ years old) reporting no history of neurological or psychiatric disorders and normal or corrected-to-normal vision, took part in the experiments. Twenty-three of them were naive as to TMS and to the purpose of the experiments, and they all participated voluntarily. The protocol was reviewed by the Inserm ethical committee and approved by an Institutional Review Board (CPP Ile de France 1).

Apparatus, stimuli, and procedure. Visual stimuli were displayed on an eye-tracker screen (Tobii Technology AB; 17 inches wide, $1024 \times 768$ ) using a laptop computer (Dell Latitude E6400) and standard stimulus presentation software (E-Prime Software). Each trial started with a gray resting screen (luminance: $75 \mathrm{~cd} / \mathrm{m}^{2}, 2500 \mathrm{~ms}$ ), followed by a fixation screen (randomly lasting between 1000 and $1500 \mathrm{~ms}$ ) (Fig. 1a). The fixation cross $\left(0.5 \times 0.5^{\circ}\right)$ was displayed in the center, along with three rectangular boxes $\left(6.0 \times 5.5^{\circ}\right)$ : one central and two lateral ones (centered $8.5^{\circ}$ to the left and right of the fixation point). Then, the fixation cross became slightly larger $\left(0.7 \times 0.7^{\circ}, 66 \mathrm{~ms}\right)$ to alert participants of an upcoming event. After an interstimulus interval $(233 \mathrm{~ms})$, a target appeared at the center of one of the two lateral boxes for a brief period of time ( $33 \mathrm{~ms})$. The target consisted of a low-contrast Gabor stimulus (2 cycles/degree spatial frequency, $3.0^{\circ}$ diameter, $0.3^{\circ}$ of $\mathrm{SD}$, minimum and maximum Michelson contrast of 0.031 and 0.283 , respectively) with its lines tilted $1^{\circ}$ to $10^{\circ}$ clockwise or counterclockwise. The intertrial interval lasted at least $4 \mathrm{~s}$.

Participants were asked to execute two tasks. The first task was to determine the orientation of the Gabor lines (discrimination task) by pressing the corresponding button on a computer keyboard ("1" for left and " 2 " for right) with the index and middle fingers of their right hand. Participants were forced to guess a response even when the target was not present or they did not consciously perceive it and accuracy was collected as outcome measure. The second task was to report whether they had consciously perceived the Gabor or not (conscious detection task). To do so, two arrow-like stimuli $(<<<$ and $>>>)$ pointing to the left and to the right were simultaneously presented below and above the fixation cross. Participants were provided with 3 keys, which they had to operate with their left hand: an upper key "d," a lower key "c," and the space bar. The upper and lower keys were associated to the arrows presented on the top and the bottom, respectively. Participants had to respond by pressing the space bar if they did not see the stimulus, or the key ("d" or "c") to select the arrow pointing to the visual hemifield (right/left) in which they perceived the target. The location of each arrow, above or below the fixation point, was randomized across trials. This task was assessed through perceptual sensitivity $\left(d^{\prime}\right)$ and response criterion (beta), two measures used in Signal Detection Theory (Green and Swets, 1966; Macmillan and Creelman, 2005). Perceptual sensitivity is a bias-free measure that informs on participants' ability to detect weak signals in situations that might be strongly influenced by belief. Response bias (beta) describes the relative preference of participants for one response over the alternative one, independently on signal strength. When participants favor neither a "yes, I saw it" response nor a "no, I did not see it" response, beta is equal to 1 . Values lower than 1 indicate a bias toward the affirmative response, whereas values $>1$ indicate a bias toward the negative response. To compute these measures, trials in which the location of a target was correctly determined by participants were considered as correct detections or "hits"; trials in which the presence of the target was not acknowledged were counted as "misses"; trials in which participants reported the location for targets that were not presented were considered "false alarms"; trials in which the target was absent and participants correctly reported not to have seen it were considered "correct rejections"; and, finally, trials in which the location of a present target was incorrectly reported were counted as "errors" and excluded from further analyses. Eye movements were monitored during each trial for fixation control purposes. Fixation was considered broken when participants' eyes position was recorded outside the central box (i.e., $3^{\circ}$ away from the fixation cross horizontally and $2.75^{\circ}$ vertically).

A titration procedure performed before the onset of the experiment allowed us to determine for each participant the stimulus contrast at which $\sim 50 \%$ of the displayed targets were consciously reported. The degree of line tilting was also adjusted to maintain discrimination accuracy between 65 and $85 \%$ of correctly reported targets. Such titration levels ensured that in both tasks, performance was halfway between the worst ( $0 \%$ in the detection task and $50 \%$ in the forced-choice discrimination task) and the best possible performance (100\% for both tasks).

Participants started the titration trials with a high contrast stimulus and, every 20 trials, target contrast and the degree of line tilting were adjusted (in steps of 0.07 Michelson contrast and $1^{\circ}$ of tilting, respectively) to converge to the preestablished criteria. The experiment started once performance levels reached those criteria. Throughout the experiment, stimulus parameters were automatically adjusted every 20 trials to maintain these titration levels.

Each block consisted of 200 trials, including 40 trials in which the target was absent. In half of the trials, a short burst of 4 TMS pulses was applied to the right FEF (active TMS trials) so that the last pulse of each burst was always delivered $16 \mathrm{~ms}$ before target onset. In the other half (sham TMS trials) the same short burst was delivered by a second TMS coil placed next to the stimulation site, with the coil surface perpendicular to the head surface, preventing the magnetic field from reaching the skull and stimulating the brain. The order of active and sham TMS trials was randomized across trials. Participants were allowed to take a short break every 40 trials and at the end of each sub-block received feedback on the screen about their performance and eye movement rates.

In two groups of participants, we explored the effects of two different stimulation frequencies, high-beta $(30 \mathrm{~Hz})$ and gamma $(50 \mathrm{~Hz})$, on visual performance. Each group performed two blocks of trials: in the frequency-specific block, 4 TMS pulses were distributed uniformly, whereas in the non-frequency-specific block, pulses were unequally distributed over the same period of time (the first and last pulses occurred at timings identical to those in the frequency-specific block, whereas the second and third pulses were slightly anticipated and delayed respectively; Fig. 1b). The order in which participants performed the two blocks was counterbalanced across participants.

Transcranial magnetic stimulation (TMS). TMS pulses were delivered using a biphasic repetitive stimulator (Superapid 2, Magstim) with a 70-mm-diameter figure-of-eight coil (Fig. 1c). A structural T1-weighted MRI scan (3T Siemens MPRAGE, flip angle $=9$, TR $=2300 \mathrm{~ms}$, TE $=$ $4.18 \mathrm{~ms}$, slice thickness $=1 \mathrm{~mm}$ ) was acquired for every participant at the CENIR (Centre de Neuro-Imagerie de Recherche) MRI center (Salpêtrière Hospital, Paris). The right FEF region was localized on each individual MRI using averaged Talairach coordinates $x=31, y=-2$, 
a
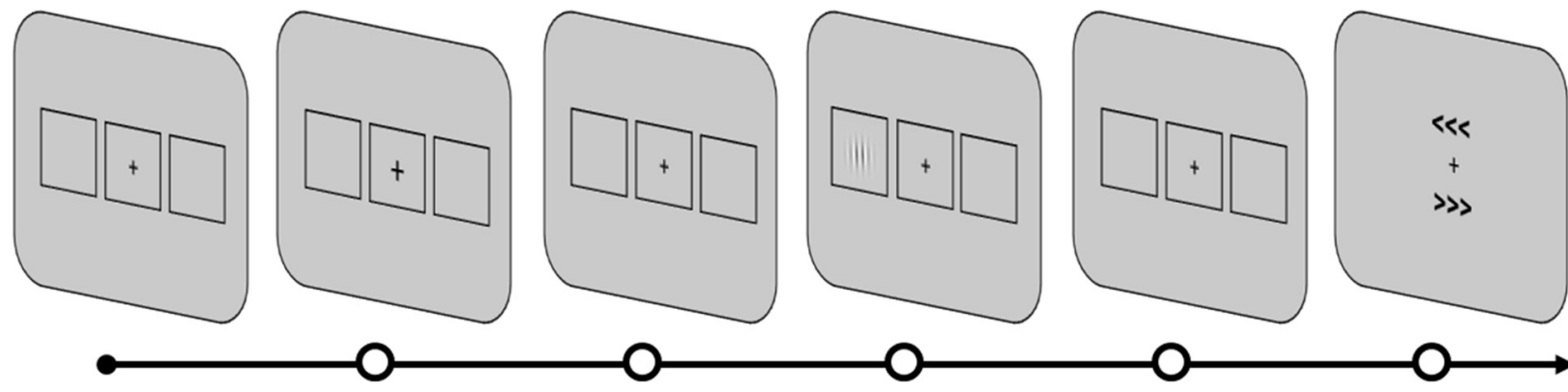

$-$

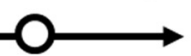

Time

Fixation

TMS

Target Discrimination Detection

b

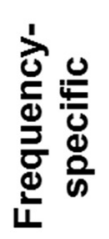

$30 \mathrm{~Hz}$

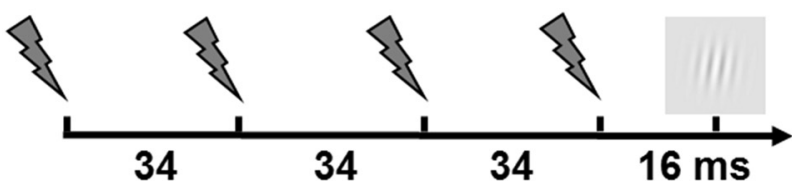

20
34

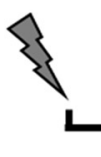

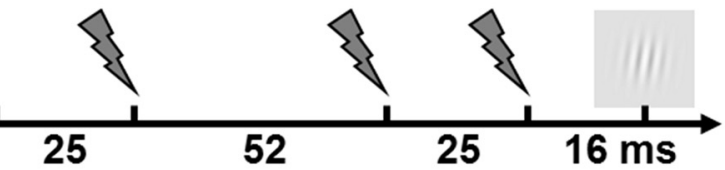

C
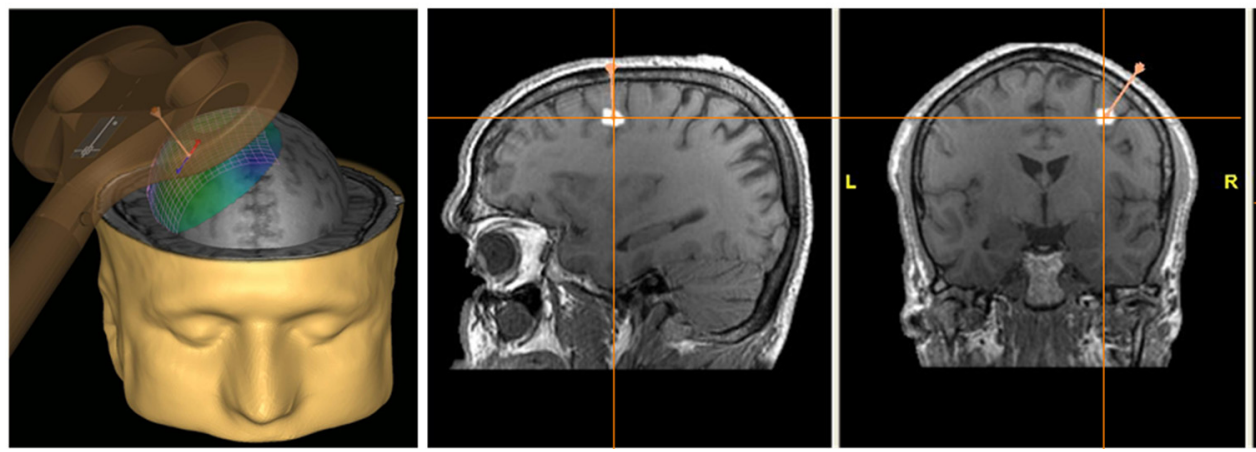

$50 \mathrm{~Hz}$
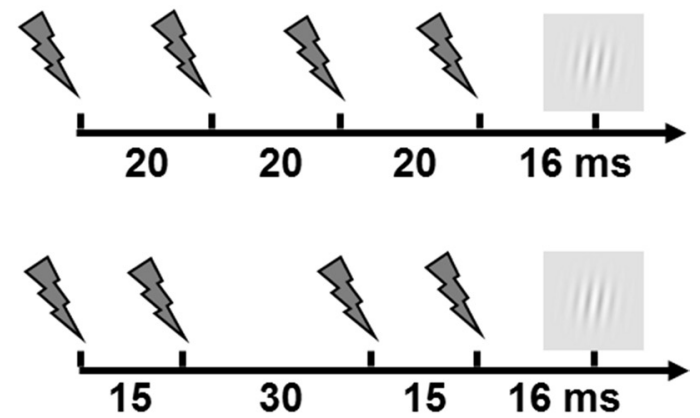

Figure 1. Experimental design. $\boldsymbol{a}$, Following a period of central fixation, a low-contrast near-threshold Gabor stimulus was briefly presented within a left or right peripheral box. Participants were requested to perform a discrimination task, indicating the orientation of the Gabor lines (left/right), followed by a conscious detection task in which they reported if they had seen or not a Gabor and where ("no" or if "yes," left/right). $\boldsymbol{b}$, Schematic drawing representing the temporal distribution of the 4 pulses of each TMS burst in frequency-specific (uniform) and non-frequency-specific (nonuniform) blocks. For each stimulation frequency $(30 \mathrm{~Hz}$ and $50 \mathrm{~Hz})$, bursts used in either block were equal in duration and number of pulses. c, TMS coil positioning on the right FEF, displayed in a representative $3 \mathrm{D}$ reconstructed native MRI brain and its associated sagittal, axial and coronal brain sections.

$z=47$ (Paus, 1996) and a $0.5 \mathrm{~cm}$ radius spherical region of interest (for details see Chanes et al., 2012). The final MRI was uploaded into a frameless stereotaxic system and reconstructed in 3D for its use in an online stereotaxic TMS neuronavigation system (eXimia NBS System, Nexstim).

At all times, the TMS coil was held tangentially to the skull, with its handle oriented $\sim 45^{\circ}$ in a rostral-to-caudal and lateral-to-medial orientation, i.e., approximately parallel to the central sulcus. Coil position was tracked online throughout the experiments and kept steady within an area of $\sim 2 \mathrm{~mm}$ radius from the targeted site. The representation of the right primary motor cortex (M1) of the abductor pollicis brevis muscle was located and the left and right motor thresholds were determined as the TMS intensity yielding thumb twitching responses in $\sim 50 \%$ of the attempts.

For all interventions, stimulation intensity was set up at $45 \%$ of the TMS machine maximal output. Nonetheless, in some participants such a level had to be slightly decreased to abolish temporal and facial muscle involuntary activations, blinks, or other types of facial sensations induced by magnetic field spread. Before the experiment, we verified on each participant that none of the TMS FEF patterns used induced contralateral motor activations on forearm or hand muscles. The average intensities at which participants were stimulated were $44.3 \%$ (SD 1.5\%) and $44.9 \%$ (SD $0.5 \%$ ) of the maximum machine output for the 30 and 50 $\mathrm{Hz}$ bursts groups, respectively (i.e., $72 \pm 13 \%$ and $74 \pm 14 \%$ of their individual motor thresholds).

Statistical analyses. Outcome measures (perceptual sensitivity and response criterion for the conscious detection task and accuracy for the discrimination task) of each group ( 30 and $50 \mathrm{~Hz}$ ) were subjected to a $2 \times$ $2 \times 2$ repeated-measures ANOVA with block (frequency- and nonfrequency-specific), target location (left and right visual field), and TMS condition (active and sham) as within-participant factors. The same ANOVA was performed for trials in which participants reported to have seen the target but incorrectly determined its location (error trials), which were eliminated from the analyses, to exclude any potential effect 


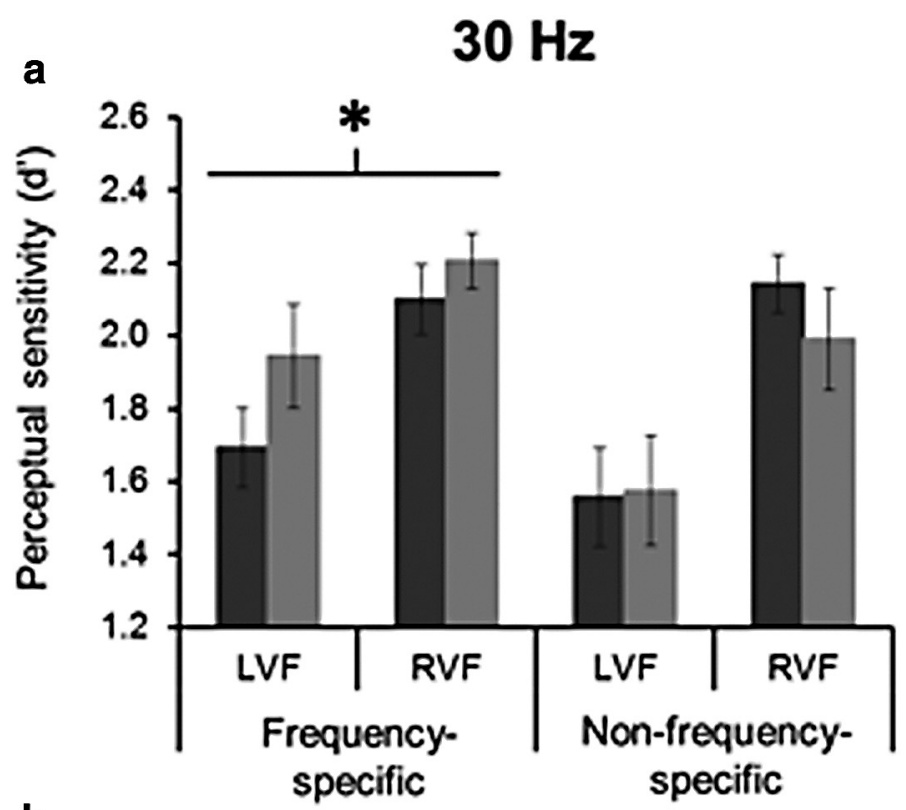

$50 \mathrm{~Hz}$

b
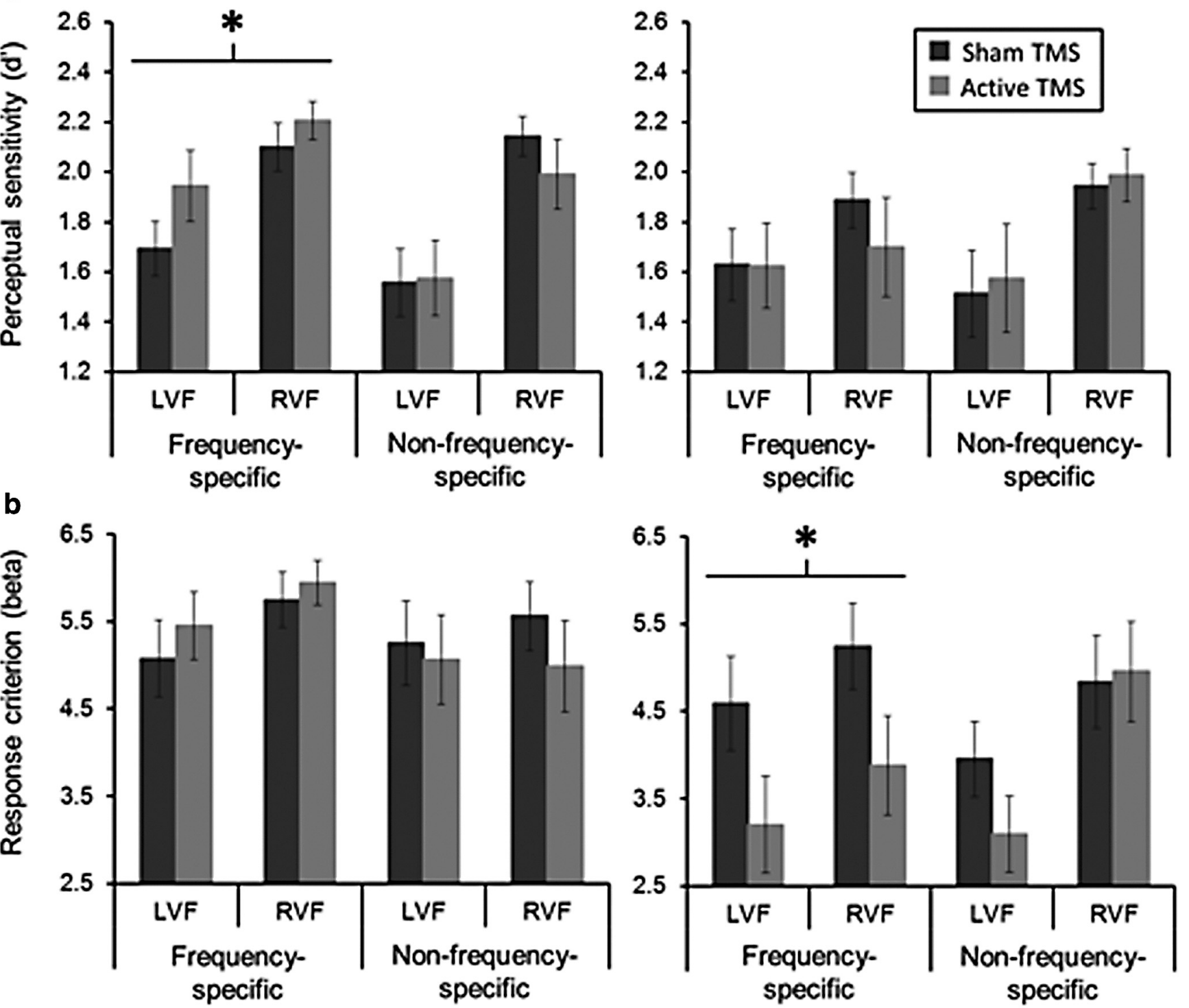

Figure 2. Impact of neurostimulation bursts at 30 and $50 \mathrm{~Hz}$ on conscious visual detection measures. $\boldsymbol{a}, \boldsymbol{b}$, Series of histograms displaying the effects of active (light gray) or sham (dark gray) frequency-specific and non-frequency-specific TMS bursts on perceptual sensitivity $(\boldsymbol{a})$ and response criterion $(\boldsymbol{b})$ values for each of the two TMS frequencies tested. Data are presented for targets displayed in the contralateral (left) and ipsilateral (right) visual fields (LVF and RVF, respectively) with regards to the stimulated right FEF region. Notice that active $30 \mathrm{~Hz}$ TMS bursts (but not their non-frequency-specific associated bursts) enhanced perceptual sensitivity $\left(d^{\prime}\right)$ compared with sham TMS patterns. Neither uniform $50 \mathrm{~Hz}$ bursts nor their associated non-frequency-specific patterns modulated this outcome measure. In contrast, active $50 \mathrm{~Hz}$ TMS bursts (but not its associated non-frequency-specific burst) relaxed response criterion for active TMS bursts compared with sham. No significant criterion differences were observed either for $30 \mathrm{~Hz}$ TMS bursts or for their associated non-frequency specific patterns. Asterisks indicate statistically significant differences for active versus sham TMS conditions.

of TMS in such trials. Finally, the factor group (30 and $50 \mathrm{~Hz}$ ) was implemented as between-participant factor in a general ANOVA with the same within-participant factors described above.

\section{Results}

One participant was excluded from the analyses in the $30 \mathrm{~Hz}$ group because broke fixation in $>50 \%$ of the trials. Trials in which participants broke fixation were eliminated from the analyses ( $8 \%$ and $5 \%$ for the 30 and $50 \mathrm{~Hz}$ groups, respectively). Moreover, error trials were also eliminated (3\% and $7 \%$ of seen targets for the 30 and $50 \mathrm{~Hz}$ groups, respectively). The repeatedmeasures ANOVA for errors did not yield any significant main effects or interactions, indicating that those were similar across conditions. The average number of trials per participant used in the analyses of each experimental condition ranged between 35 and 38 (mean \pm SD: $36 \pm 4$ ). In the discrimination task, participants' general accuracy was $63 \%$ and $64 \%$ for the $30 \mathrm{~Hz}$ and 50 $\mathrm{Hz}$ groups, respectively. As expected, it was high when they reported to have seen the target ( $75 \%$ and $76 \%$, respectively), and it remained at chance levels when they reported not to have seen it (50\% for both groups).

Our data revealed frequency-specific contributions of FEF activity to visual performance (Fig. 2; Table 1). For the conscious detection task, active TMS bursts delivered at $30 \mathrm{~Hz}$, but not at the matched non-frequency-specific patterns, improved participants' perceptual sensitivity (significant interaction between block and TMS condition, $\left.F_{(1,12)}=6.07, p=0.030\right)$. Scores were higher for 
Table 1. Summary of main statistical effects and interactions of the different neurostimulation patterns on conscious visual detection

\begin{tabular}{|c|c|c|c|c|c|}
\hline \multirow[b]{2}{*}{ Group } & \multirow{2}{*}{$\begin{array}{l}\text { Main effects and } \\
\text { interactions }\end{array}$} & \multicolumn{2}{|c|}{$\begin{array}{l}\text { Perceptual sensitivity } \\
\left(d^{\prime}\right)\end{array}$} & \multicolumn{2}{|c|}{$\begin{array}{l}\text { Response criterion } \\
\text { (beta) }\end{array}$} \\
\hline & & $F$ & $p$ & $F$ & $p$ \\
\hline \multirow[t]{7}{*}{$30 \mathrm{~Hz}$} & Block & 6.328 & $0.027^{*}$ & 0.715 & 0.414 \\
\hline & Side & 10.978 & $0.006^{*}$ & 1.770 & 0.208 \\
\hline & TMS & 0.576 & 0.463 & 0.056 & 0.816 \\
\hline & Block $\times$ Side & 1.219 & 0.291 & 1.584 & 0.232 \\
\hline & Block $\times$ TMS & 6.072 & $0.030^{*}$ & 3.897 & 0.072 \\
\hline & Side $\times$ TMS & 2.178 & 0.166 & 1.055 & 0.325 \\
\hline & Block $\times$ Side $\times$ TMS & 0.013 & 0.911 & 0.045 & 0.836 \\
\hline \multirow[t]{7}{*}{$50 \mathrm{~Hz}$} & Block & 0.229 & 0.641 & 0.002 & 0.968 \\
\hline & Side & 2.180 & 0.164 & 8.069 & $0.014^{*}$ \\
\hline & TMS & 0.048 & 0.830 & 7.948 & $0.014^{*}$ \\
\hline & Block $\times$ Side & 1.666 & 0.219 & 1.005 & 0.334 \\
\hline & Block $\times$ TMS & 1.776 & 0.205 & 6.418 & $0.025^{*}$ \\
\hline & Side $\times$ TMS & 0.866 & 0.369 & 0.486 & 0.498 \\
\hline & Block $\times$ Side $\times$ TMS & 0.288 & 0.601 & 0.973 & 0.342 \\
\hline
\end{tabular}

All statistically significant main effects and interactions (repeated-measures ANOVA) are indicated in thetable by an asterisk $\left({ }^{*} p<0.05\right)$. In addition to the significant interaction between block and TMS condition reported, for $30 \mathrm{~Hz}$ TMS patterns and its associated non-frequency-specific bursts: perceptual sensitivity was higher for targets displayed to the right than to the left visual field $\left(\mathrm{F}_{(1,12)}=10.98, p=0.006\right)$ and for frequency-specific (or uniform) blocks than for non-frequencyspecific (or non-uniform) blocks $\left(F_{(1,12)}=6.33, p=0.027\right.$ ). For the $50 \mathrm{~Hz}$ TMS pattern (and their corresponding nonfrequency-specific or non-uniform bursts), in addition to the significant interaction between block and TMS condition reported, response criterion was more relaxed for targets displayed to the left than to the right visual field $\left(F_{(1,13)}=8.07\right.$, $p=0.014)$ and with active than sham TMS bursts $\left(F_{(1,13)}=7.95, p=0.014\right)$.

active than for sham TMS only when pulses were uniformly delivered at $30 \mathrm{~Hz}$ (planned comparison active vs sham for the frequencyspecific block: $F=5.55, p=0.036$ ), but not when non-uniform patterns were used (planned comparison active vs sham for the nonfrequency-specific block: $F<1$ ) (Fig. $2 a$, left). Moreover, no significant main effects or interactions were observed for the response criterion (Fig. 2b, left). In the discrimination task, no significant modulations of accuracy were observed in any of the blocks.

On the other hand, TMS bursts delivered at $50 \mathrm{~Hz}$ and their corresponding non-frequency-specific patterns proved unable to modulate perceptual sensitivity $\left(d^{\prime}\right)$ in the conscious detection task (Fig. 2a, right). However, the uniform pattern shifted response criterion (significant interaction between block and TMS condition, $\left.F_{(1,13)}=6.42, p=0.025\right)$. Active $50 \mathrm{~Hz}$ TMS bursts decreased the strictness of participants' response criterion compared with sham TMS (planned comparison active vs sham for the frequency-specific block: $F=13.37, p=0.003$ ), whereas no significant differences in response criterion were observed when TMS bursts were delivered at their associated non-frequencyspecific pattern (planned comparison active vs sham for the nonfrequency-specific block: $F=1.05, p=0.325$ ) (Fig. $2 b$, right). In the discrimination task, no main effects or interactions were observed.

Finally, the significant interaction between group $\times$ block $\times$ TMS condition for both perceptual sensitivity $(F=6.84, p=$ $0.015)$ and response criterion $(F=10.14, p<0.01)$ when group $(30$ and $50 \mathrm{~Hz}$ ) was integrated as between-participant factor in a general ANOVA emphasizes the frequency specificity of the TMS impact.

\section{Discussion}

Our findings shed novel light on the oscillatory basis underlying visual detection behavior for near-threshold stimuli and suggest distinct modulatory roles for high-beta and gamma frontal activity in visual performance.

Frontal $30 \mathrm{~Hz}$ TMS bursts impacted perceptual sensitivity $\left(d^{\prime}\right)$ in a conscious visual detection task, whereas $50 \mathrm{~Hz}$ TMS patterns yielded changes in response criterion. Beta oscillations from the
FEF have been previously correlated with modulations of visual performance (Gross et al., 2004; Donner et al., 2007), and we thereby show here that such activity could be causally linked to these behavioral effects. These oscillations may reflect reverberant activity within and among visual, frontoparietal and frontal motor cortices (Engel and Fries, 2010), which might facilitate the accumulation and maintenance of sensory evidence for decisionmaking (Donner et al., 2007; Siegel et al., 2011). Importantly, our data provide direct proof that the processing of visual sensory evidence could be episodically enhanced by an extrinsic source of neural synchronization, such as TMS, tuned to a specific oscillation frequency.

Patterns at $50 \mathrm{~Hz}$ over the right FEF specifically decreased response criterion when detecting faint near-threshold stimuli. This finding is consistent with prior work showing a correlation between prestimulus gamma-band oscillations in occipital regions and decision biases (Wyart and Tallon-Baudry, 2009). We now extend this result to frontal regions, and, most importantly, we hypothesize a causal contribution of gamma-band oscillations to such processes. The modulation of these phenomena by stimulus features reported previously suggests that oscillatory activity at this frequency band is likely to reflect sensory evidence (Frien et al., 2000; Siegel and König, 2003; Kayser and König, 2004; Hall et al., 2005; Henrie and Shapley, 2005; Hoogenboom et al., 2006; Liu and Newsome, 2006; Vidal et al., 2006; Siegel et al., 2007; Berens et al., 2008; Wyart and Tallon-Baudry, 2008, 2009). Accordingly, we hypothesize that the induction of a brief lowgamma pretarget pattern on a higher cortical region, such as the right FEF, holding connections with the visual cortex, may have been encoded as sensory evidence, and thus favored a conscious affirmative detection response ("Yes I saw it") over a negative one ("No I did not see it") for near-threshold targets, independent of stimulus presence, hence decreasing the strictness of the response criterion.

The double dissociation observed between stimulation frequency ( $30 \mathrm{~Hz}$ vs $50 \mathrm{~Hz}$ bursts) and behavioral outcome measure (perceptual sensitivity vs response criterion), together with the lack of behavioral modulations when the same activity (equal number of TMS pulses delivered across the same interval at identical stimulation intensity) was induced by a slightly different TMS pattern indicate that the observed effects are a specific consequence of stimulation frequency, rather than depend on the total amount of activity induced within a critical time window. Furthermore, none of our interventions proved able to modulate the visual discrimination task, suggesting that the induced activity might not impact visual performance at a purely perceptual level but could rather operate on conscious access. Alternatively, the discrimination task could not have been modulated simply because it might require more refined processing and accumulation of more evidence.

In sum, our results provide causal evidence that characteristic spatiotemporal activity patterns induced by neurostimulation to the same cerebral region can yield exquisitely distinct behavioral outcomes such as increases of visual sensitivity and decreases of response criterion. Such evidence may reflect a general brain mechanism to multiplex functions within the same neural substrate (Thut et al., 2012). Findings coherent with this notion have been reported for parietal TMS bursts delivered at lower stimulation frequencies (Romei et al., 2010, 2011). Similarly, recordings in nonhuman primates have provided correlational evidence of enhanced gamma frequency synchrony between frontal and posterior parietal regions during exogenous attention in a pop-out visual detection task, and synchrony increases at the high-beta range between these 
same areas during endogenous attentional orienting, as tested in a visual search paradigm (Buschman and Miller, 2007, 2009). Similar to the current data, such evidence in the field of attentional orienting supports the hypothesis that characteristic synchronization patterns emerging from the FEF may underlie different cognitive processes, leading to different behavioral outcomes.

Finally, our data show that perceptual sensitivity in healthy participants can be episodically enhanced by an extrinsic source of neural synchronization tuned to a specific frequency and support future uses of non-invasive neurostimulation to probe and manipulate oscillatory phenomena in the human brain from circumscribed cortical regions. Furthermore, pathological conditions involving specific alterations of cerebral oscillations (Thut et al., 2012) associated with impaired cognitive performance could potentially benefit from the use of frequency-tailored neurostimulation to locally manipulate activity and restore the characteristic oscillation frequencies of the healthy system.

\section{References}

Berens P, Keliris GA, Ecker AS, Logothetis NK, Tolias AS (2008) Feature selectivity of the gamma-band of the local field potential in primate primary visual cortex. Front Neurosci 2:199-207. CrossRef Medline

Buschman TJ, Miller EK (2007) Top-down versus bottom-up control of attention in the prefrontal and posterior parietal cortices. Science 315: 1860-1862. CrossRef Medline

Buschman TJ, Miller EK (2009) Serial, covert shifts of attention during visual search are reflected by the frontal eye fields and correlated with population oscillations. Neuron 63:386-396. CrossRef Medline

Chanes L, Chica AB, Quentin R, Valero-Cabré A (2012) Manipulation of pre-target activity on the right frontal eye field enhances conscious visual perception in humans. PLoS One 7:e36232. CrossRef Medline

Chica AB, Lasaponara S, Chanes L, Valero-Cabré A, Doricchi F, Lupiáñez J, Bartolomeo P (2011) Spatial attention and conscious perception: the role of endogenous and exogenous orienting. Atten Percept Psychophys 73:1065-1081. CrossRef Medline

Corbetta M, Shulman GL (2002) Control of goal-directed and stimulusdriven attention in the brain. Nat Rev Neurosci 3:201-215. Medline

Corbetta M, Patel G, Shulman GL (2008) The reorienting system of the human brain: from environment to theory of mind. Neuron 58:306-324. CrossRef Medline

Donner TH, Siegel M, Oostenveld R, Fries P, Bauer M, Engel AK (2007) Population activity in the human dorsal pathway predicts the accuracy of visual motion detection. J Neurophysiol 98:345-359. CrossRef Medline

Engel AK, Fries P (2010) Beta-band oscillations-signalling the status quo? Curr Opin Neurobiol 20:156-165. CrossRef Medline

Feurra M, Paulus W, Walsh V, Kanai R (2011) Frequency specific modulation of human somatosensory cortex. Front Psychol 2:13. Medline

Frien A, Eckhorn R, Bauer R, Woelbern T, Gabriel A (2000) Fast oscillations display sharper orientation tuning than slower components of the same recordings in striate cortex of the awake monkey. Eur J Neurosci 12:14531465. CrossRef Medline

Fries P (2009) Neuronal gamma-band synchronization as a fundamental process in cortical computation. Annu Rev Neurosci 32:209-224. CrossRef Medline

Fries P, Reynolds JH, Rorie AE, Desimone R (2001) Modulation of oscillatory neuronal synchronization by selective visual attention. Science 291: 1560-1563. CrossRef Medline

Green D, Swets J (1966) Signal detection theory and psychophysics. New York: Wiley.

Gregoriou GG, Gotts SJ, Zhou H, Desimone R (2009) High-frequency, long-range coupling between prefrontal and visual cortex during attention. Science 324:1207-1210. CrossRef Medline

Grosbras MH, Paus T (2003) Transcranial magnetic stimulation of the hu- man frontal eye field facilitates visual awareness. Eur J Neurosci 18:31213126. CrossRef Medline

Gross J, Schmitz F, Schnitzler I, Kessler K, Shapiro K, Hommel B, Schnitzler A (2004) Modulation of long-range neural synchrony reflects temporal limitations of visual attention in humans. Proc Natl Acad Sci U S A 101: 13050-13055. CrossRef Medline

Hall SD, Holliday IE, Hillebrand A, Singh KD, Furlong PL, Hadjipapas A, Barnes GR (2005) The missing link: analogous human and primate cortical gamma oscillations. Neuroimage 26:13-17. CrossRef Medline

Henrie JA, Shapley R (2005) LFP power spectra in V1 cortex: the graded effect of stimulus contrast. J Neurophysiol 94:479-490. CrossRef Medline

Hoogenboom N, Schoffelen JM, Oostenveld R, Parkes LM, Fries P (2006) Localizing human visual gamma-band activity in frequency, time and space. Neuroimage 29:764-773. CrossRef Medline

Kanai R, Chaieb L, Antal A, Walsh V, Paulus W (2008) Frequency-dependent electrical stimulation of the visual cortex. Curr Biol 18:1839-1843. CrossRef Medline

Kayser C, König P (2004) Stimulus locking and feature selectivity prevail in complementary frequency ranges of V1 local field potentials. Eur J Neurosci 19:485-489. CrossRef Medline

Klimesch W, Sauseng P, Gerloff C (2003) Enhancing cognitive performance with repetitive transcranial magnetic stimulation at human individual alpha frequency. Eur J Neurosci 17:1129-1133. CrossRef Medline

Libedinsky C, Livingstone M (2011) Role of prefrontal cortex in conscious visual perception. J Neurosci 31:64-69. CrossRef Medline

Liu J, Newsome WT (2006) Local field potential in cortical area MT: stimulus tuning and behavioral correlations. J Neurosci 26:7779-7790. CrossRef Medline

Macmillan N, Creelman C (2005) Detection theory: a user's guide, Ed 2. London: Erlbaum Associates.

Moore T, Armstrong KM (2003) Selective gating of visual signals by microstimulation of frontal cortex. Nature 421:370-373. CrossRef Medline

Paus T (1996) Location and function of the human frontal eye-field: a selective review. Neuropsychologia 34:475-483. CrossRef Medline

Romei V, Gross J, Thut G (2010) On the role of prestimulus alpha rhythms over occipito-parietal areas in visual input regulation: correlation or causation? J Neurosci 30:8692-8697. CrossRef Medline

Romei V, Driver J, Schyns PG, Thut G (2011) Rhythmic TMS over parietal cortex links distinct brain frequencies to global versus local visual processing. Curr Biol 21:334-337. CrossRef Medline

Siegel M, König P (2003) A functional gamma-band defined by stimulusdependent synchronization in area 18 of awake behaving cats. J Neurosci 23:4251-4260. Medline

Siegel M, Donner TH, Oostenveld R, Fries P, Engel AK (2007) Highfrequency activity in human visual cortex is modulated by visual motion strength. Cereb Cortex 17:732-741. Medline

Siegel M, Engel AK, Donner TH (2011) Cortical network dynamics of perceptual decision-making in the human brain. Front Hum Neurosci 5:21. Medline

Thut G, Veniero D, Romei V, Miniussi C, Schyns P, Gross J (2011) Rhythmic TMS causes local entrainment of natural oscillatory signatures. Curr Biol 21:1176-1185. CrossRef Medline

Thut G, Miniussi C, Gross J (2012) The functional importance of rhythmic activity in the brain. Curr Biol 22:R658-R663. CrossRef Medline

Vidal JR, Chaumon M, O’Regan JK, Tallon-Baudry C (2006) Visual grouping and the focusing of attention induce gamma-band oscillations at different frequencies in human magnetoencephalogram signals. J Cogn Neurosci 18:1850-1862. CrossRef Medline

Wagner T, Valero-Cabre A, Pascual-Leone A (2007) Noninvasive human brain stimulation. Annu Rev Biomed Eng 9:527-565. CrossRef Medline

Wyart V, Tallon-Baudry C (2008) Neural dissociation between visual awareness and spatial attention. J Neurosci 28:2667-2679. CrossRef Medline

Wyart V, Tallon-Baudry C (2009) How ongoing fluctuations in human visual cortex predict perceptual awareness: baseline shift versus decision bias. J Neurosci 29:8715-8725. CrossRef Medline 